\title{
p-Coumaric acid, a common dietary phenol, inhibits platelet activity in vitro and in vivo
}

\author{
Cristina Luceri ${ }^{1}$, Lucia Giannini ${ }^{1}$, Maura Lodovici ${ }^{1}$, Emilia Antonucci ${ }^{2}$, Rosanna Abbate ${ }^{2}$, \\ Emanuela Masini ${ }^{1}$ and Piero Dolara ${ }^{1}$ \\ ${ }^{1}$ Department of Preclinical and Clinical Pharmacology, University of Florence, Azienda Ospedaliero-Universitaria Careggi, \\ 50139 Florence, Italy \\ ${ }^{2}$ Thrombosis Center, University of Florence, Azienda Ospedaliero-Universitaria Careggi, 50139 Florence, Italy
}

(Received 22 March 2006 - Revised 4 August 2006 - Accepted 5 September 2006)

\begin{abstract}
p-Coumaric acid (3-(4-hydroxyphenyl)-2-propenoic acid; 4CA), is a ubiquitous plant metabolite with antioxidant and anti-inflammatory properties. The antiplatelet activity of this compound was analysed both ex vivo and in vitro. 4-CA, administered to rabbits for 2 weeks at the dose of $5 \mathrm{mg} / \mathrm{kg}$, mixed with food, inhibited ADP-induced platelet aggregation without affecting blood coagulation. This effect was associated with a marked increase in plasma antioxidant activity, measured as ferric reducing ability of plasma, and with the reduction of thromboxane $\mathrm{B}_{2}$ production. The antiplatelet effect was confirmed by in vitro experiments on human blood: 4CA (500 $\mu \mathrm{M}$ and $1 \mathrm{mM})$ reduced ADP-induced platelet aggregation (55.2 (SE 4.01) \% and 35.6 (SE 2.35) \% relative to basal level, respectively). 4CA was able to modify platelet function, measured with PFA-100 ${ }^{\mathrm{TM}}$, a shear-inducing device that simulates primary haemostasis. 4CA interfered also with arachidonic acid cascade, reducing thromboxane $\mathrm{B}_{2}$ production and lipopolysaccharide-induced prostaglandin $\mathrm{E}_{2}$ generation ( $\mathrm{IC}_{50} 371$ and $126 \mu \mathrm{M}$, respectively). The data show that $4 \mathrm{CA}$ is an antioxidant compound with good antiplatelet activity at doses that can be obtained with dietary intervention, suggesting possible applications for primary prevention of vascular disease.
\end{abstract}

Phenols: Platelet aggregation: Antioxidant activity

Epidemiological studies suggest that moderate red wine consumption may reduce the risk of CVD (de Gaetano \& Cerletti, 2001) and this effect can be partially due to some naturally occurring constituents of this beverage. Wine contains a wide variety of polyphenols, including tannins, anthocyanins and phenolic flavonoids (including flavonols and flavones) (Rasmussen et al. 2005) that may contribute to the cardioprotective effects of grape products, as suggested by several studies (Duffy et al. 2001; da Luz \& Coimbra, 2004; Vita, 2005).

One proposed mechanism of the apparent benefit of various sources of polyphenols is their favourable effect on platelet aggregation (Ruf, 2004; Cordova et al. 2005). Platelet aggregation plays a critical role in the pathogenesis of vascular disorders, and there is evidence that antiplatelet therapy reduces the risk of CVD (Youssef et al. 2005).

Polyphenols may inhibit platelet aggregation through a number of different mechanisms, including inhibition of cyclooxygenase (COX), lipoxygenase (Schubert et al. 1999; Hong et al. 2001) and phosphodiesterase activities (Dell'Agli et al. 2005). Inhibition of phosphodiesterase activity, increasing platelet levels of cAMP or cGMP, lowers platelet calcium levels and inhibits platelet activation both in vitro and in vivo (Demrow et al. 1995).
Other inhibitory effects of polyphenols on platelet aggregation include scavenging of reactive oxygen species such as superoxide anion (Frei \& Higdon, 2003), decreasing phospholipase C (Pignatelli et al. 2000) and inhibition of lipid peroxidation (Aviram et al. 2002).

A relevant effect of polyphenols on the cardiovascular system could be due to their ability to interact with the L-arginine-nitric oxide pathway leading to the generation of NO from vascular endothelium (Andriambeloson et al. 1997), since this molecule has vasorelaxant and antiaggregation properties. Freedman et al. (2001) examined the effects of grape juice on platelet function, observing that the addition of grape juice to platelets ex vivo was associated with a decrease in the production of superoxide anion from platelets, a reduction in their aggregation and a significant increase in platelet NO production, effects related to reduced activation of protein kinase $\mathrm{C}$. The findings were also reproduced in vivo in platelets isolated from healthy volunteers who had consumed grape juice $(7 \mathrm{ml} / \mathrm{kg}$ perd) for 2 weeks (Freedman et al. 2001). Grape seed and grape skin, in combination, exhibited a high antiplatelet effect in vitro and ex vivo, in dog platelets at doses ranging between 2 and $20 \mathrm{mg} / \mathrm{kg}$ (Shanmuganayagam et al. 2002).

\footnotetext{
Abbreviations: AA, arachidonic acid; 4CA, p-coumaric acid; COX, cyclooxygenase; $\mathrm{PGE}_{2}$, prostaglandin $\mathrm{E}_{2}$; $\mathrm{PRP}_{\text {, platelet-rich plasma; } \mathrm{TXB}}$, thromboxane $\mathrm{B}_{2}$. * Corresponding author: Dr Cristina Luceri, fax +39055 4271 280, email cristina.luceri@unifi.it
} 
Results of studies on the effect of red or white wine consumption on platelet aggregation are contrasting (Pignatelli et al. 2002). Some studies have focused on the effect of single wine constituents such as resveratrol, a phytoalexin present at low concentration in grapes and some wines, which is able to reduce several platelet functions (Olas et al. 2002), and the flavonoid quercetin, which inhibits collagen-induced platelet aggregation and adhesion (Pignatelli et al. 2000; Kikura et al. 2004).

p-Coumaric acid (3-(4-hydroxyphenyl)-2-propenoic acid; $4 \mathrm{CA}$ ) is another wine constituent, widely distributed in cereals, fruits and vegetables (being a ubiquitous plant metabolite), intermediate in the synthesis of many phenols (Clifford, 2000). Studies performed in our laboratory demonstrate that 4CA has marked antioxidant and anti-inflammatory properties in rat colonic mucosa (Guglielmi et al. 2003; Luceri et al. 2004).

The purpose of the present study was to evaluate the effects of 4CA on systemic oxidant-antioxidant status and on platelet function.

\section{Materials and methods}

Venous blood was sampled from rabbits and healthy human volunteers using a 21-gauge needle (Pentaven ${ }^{\circledR}$; Pentaferte, Campli, Teramo, Italy) and collected in evacuated polypropylene tubes containing $3.8 \%$ sodium citrate $(9: 1$, v/v; Vacuette ${ }^{\circledR}$; Greiner bio-one, Kremsmünster, Austria) or EDTA (Vacutest ${ }^{\circledR}$; Vacutest Kima, Azzergrande, Padova, Italy).

4CA and arachidonic acid (AA) were purchased from the Sigma Chemical Co. (St Louis, MO, USA) and ADP was purchased from Mascia Brunelli (Milan, Italy). Thromboxane $\mathrm{B}_{2}$ $\left(\mathrm{TXB}_{2}\right)$ and prostaglandin $\mathrm{E}_{2}\left(\mathrm{PGE}_{2}\right)$ enzyme immunoassay kits were obtained from the Cayman Chemical Co. (Ann Arbor, MI, USA).

\section{Ex vivo studies in rabbit blood}

All the procedures adopted were carried out in agreement with the European Union Regulations on the Care and Use of Laboratory Animals (OJ of ECL 358/1, 12/18/1986) and the experiments were conducted according to Italian regulations on the protection of animals used for experimental and other scientific purposes (DM 116/1992). Blood samples from rabbits were obtained by puncture of an ear vein.

The first experiment was a dose-response study: twelve albino rabbits $(2.5-3 \mathrm{~kg})$ obtained from Charles River (Lecco, Italy) were randomly divided into three groups of four animals, each housed in a single cage: controls were fed a powdered standard lab chow purchased from Harlan (Milan, Italy), the 2030 Global Diet for rabbits, whereas the treated groups received the same diet enriched with 4CA; the proper amount of 4CA was mixed with the daily dietary mass $(190 \mathrm{~g})$ to a final dosage of 5 and $500 \mathrm{mg} / \mathrm{kg}$, for 4 weeks.

The second experiment was a time-course study, performed using the lowest effective 4CA dose $(5 \mathrm{mg} / \mathrm{kg})$. Blood samples were obtained from five rabbits at time 0 and then after $2,4,6$, 8 and 10 weeks of treatment.

Platelet aggregation. At the indicated time-points, blood samples were collected from rabbits into tubes containing
$3.8 \%$ trisodium citrate solution (9:1, v/v). Platelet-rich plasma (PRP) was obtained by centrifuging the blood samples $\left(80 \mathrm{~g}, 10 \mathrm{~min}, 20^{\circ} \mathrm{C}\right)$. After PRP removal, the remaining plasma was centrifuged $\left(900 \mathrm{~g}, 10 \mathrm{~min}, 20^{\circ} \mathrm{C}\right)$ and the supernatant was collected to obtain platelet-poor plasma, used to dilute autologous PRP and to equilibrate the aggregometer. Platelet aggregation was determined by a four-channel aggregometer (model PAP-4; Biodata Corporation, Horsham, PA, USA) according to the method of Born (1962). Aggregation was induced by the addition of ADP or AA (final concentrations 3 and $2.86 \mathrm{mM}$, respectively). Aggregation was measured over $5 \mathrm{~min}$ and the extent of aggregation was estimated by measuring the maximal curve height above the baseline level.

Determination of anticoagulant activity. An aliquot of venous blood samples collected into citrate-containing tubes was used to determine prothrombin time and activated partial thromboplastin time, using a coagulometer (Dade Behring, Newark, DE, USA).

Whole blood cell counts. Blood cell counts, Hb concentration, haematocrit value and mean platelet volume were measured in whole blood collected in EDTA-containing tubes, using a haematology analyser (Coulter Electronics, Hialeah, FL, USA).

Antioxidant activity. Plasma total antioxidant power (ferric reducing ability of plasma) measures the ability of the antioxidants contained in a sample to reduce ferric ions (Benzie \& Strain, 1996). The method is based on the reduction of a ferric-tripyridyltriazine [Fe(III)-tripyridyltriazine] complex to the ferrous [Fe(II)] form, which has an absorption maximum at $593 \mathrm{~nm}$. Fe(III) is used in excess so that the colour formation is linearly related to the amount of reductant (antioxidant) present. Data are expressed as $\mu \mathrm{mol} / \mathrm{l}$.

Thromboxane $B_{2}$ release from activated platelets. $\mathrm{TXB}_{2}$, the stable metabolite of thromboxane $\mathrm{A}_{2}$ released during aggregation, was used as an index of COX-1 activity (Patrignani et al. 1994). Immediately after platelet aggregation induced by ADP or AA, the tubes containing PRP were transferred to an ice bath and later centrifuged in an Eppendorf microcentrifuge for $5 \mathrm{~min}$. The supernatant was collected and frozen at $-20^{\circ} \mathrm{C}$ for the determination of $\mathrm{TXB}_{2}$ concentration by enzyme immunoassay kit, according to the manufacturer's instructions.

\section{In vitro study in human blood}

The study protocol followed our institutional guidelines and an informed consent was obtained from each subject. Ten healthy, non-smoking volunteers (six women, four men) aged 23-39 years participated in the study. None of the participants had reported previous CVD, metabolic or systemic disease, or had taken any drug in the 2 weeks before the study. Women were premenopausal and were not taking oestrogens.

Venous blood was carefully drawn from an antecubital vein by trauma-free venepucture with rapid flow of blood. Within $10 \mathrm{~min}$, whole blood was incubated for $60 \mathrm{~min}$ at room temperature with $4 \mathrm{CA}$ (dissolved in $2 \% 1 \mathrm{M}-\mathrm{NaOH}$ ) or the vehicle alone. 4CA final concentrations were 10, 100, 500 and $1000 \mu \mathrm{M}$. 
Platelet aggregation. After $60 \mathrm{~min}$ incubation with 10, 100,500 and $1000 \mu \mathrm{M}-4 \mathrm{CA}$, blood samples were centrifuged $\left(160 \mathrm{~g}, 10 \mathrm{~min}, 20^{\circ} \mathrm{C}\right)$ and the supernatant separated as PRP. After PRP removal, the remaining plasma was centrifuged $\left(2000 \mathrm{~g}, 10 \mathrm{~min}, 20^{\circ} \mathrm{C}\right)$ and the supernatant was separated to obtain platelet-poor plasma. PRP was diluted to $2-3 \times 10^{11}$ platelets/l with autologous platelet-poor plasma. Platelet aggregation was performed at $37^{\circ} \mathrm{C}$ using a four-channel photometric aggregometer (model PAP-4; Biodata Corporation) based on the method of Born (1962). Aggregation was induced by ADP (final concentration $3 \mu \mathrm{M}$ ). This concentration was chosen to ensure a high probability of aggregation based on previous experience. The aggregation was allowed to proceed for $5 \mathrm{~min}$ and the extent was estimated quantitatively by measuring the maximal curve height above baseline level.

Whole blood cell counts. Whole blood cell counts were measured as described earlier for rabbit samples.

PFA-100 ${ }^{\mathrm{TM}}$ closure time. Citrated whole blood samples incubated at room temperature for $60 \mathrm{~min}$ with $500 \mu \mathrm{M}$ or $1 \mathrm{mM} 4 \mathrm{CA}$ were analysed by PFA-100 ${ }^{\mathrm{TM}}$ (Dade Behring), a high-shear-inducing device that simulates primary haemostasis. We determined closure times on duplicate samples of $800 \mu \mathrm{l}$ using cartridges containing collagen-epinephrine or collagen-ADP membranes.

Prostaglandin $E_{2}$ production. Plasma $\mathrm{PGE}_{2}$ levels were determined as an index of whole blood COX-2 activity. Aliquots of citrated whole blood were incubated with 4CA (dissolved in $2 \% 1 \mathrm{M}-\mathrm{NaOH}$ ) or the vehicle alone, in the presence of endotoxin (lipopolysaccharide) derived from Escherichia coli 026:B6 (Sigma Chemical Co.) at $37^{\circ} \mathrm{C}$ for 60 min. The contribution of platelet COX-1 was suppressed by the addition of $200 \mu \mathrm{M}$-aspirin (Patrignani et al. 1994). The final concentrations of 4CA were 10, 100, 500 $\mu \mathrm{M}$ and $1 \mathrm{~mm}$. Aliquots of citrated whole blood were incubated with celecoxib (final concentration $1 \mu \mathrm{M}$ ) in the presence of $10 \mu \mathrm{g} / \mathrm{ml}$ lipopolysaccharide, as positive control. Plasma was separated by centrifugation $\left(1000 \mathrm{~g}, 20 \mathrm{~min}, 20^{\circ} \mathrm{C}\right)$ and assayed for $\mathrm{PGE}_{2}$ using an enzyme immunoassay kit according to the manufacturer's instructions.

Thromboxane $B_{2}$ release from human activated platelets. The determination of $\mathrm{TXB}_{2}$ production was performed as described earlier for rabbit samples.

\section{Statistical analysis}

Experiments were performed at least in duplicate and the results were expressed as means and their staandard errors. Statistical analysis was conducted using a two-way ANOVA.

\section{Results}

\section{Ex vivo studies in rabbit blood}

Inhibitory effects of $4 C A$ on platelet aggregation. The doseresponse study was performed using two extreme doses: 5 and $500 \mathrm{mg} / \mathrm{kg}$ 4CA, chosen considering that the estimated human daily intake of $4 \mathrm{CA}$ is about $15 \mathrm{mg} / \mathrm{kg}$. At both doses $4 \mathrm{CA}$ was able to inhibit AA-induced platelet aggregation in a not statistically significant dose-dependent way (Fig. 1).

In the second experiment we observed that ADP-induced platelet aggregation was inhibited by $4 \mathrm{CA}(5 \mathrm{mg} / \mathrm{kg})$ in a

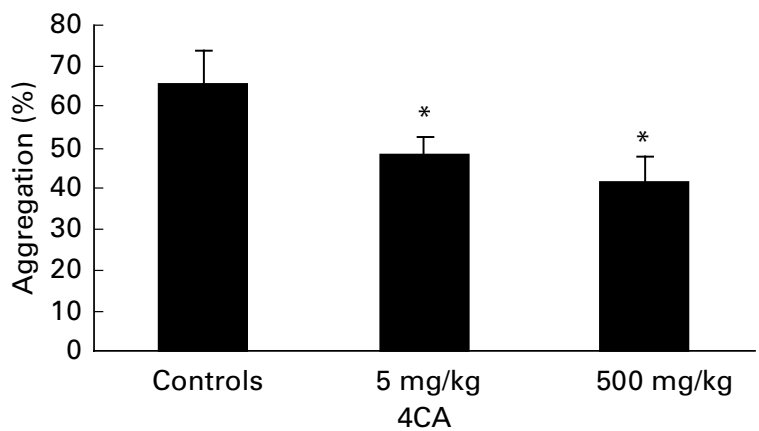

Fig. 1. Inhibition of platelet aggregation in blood samples from rabbits fed a standard diet (controls) or a diet enriched with $p$-coumaric acid (4CA; 5 and $500 \mathrm{mg} / \mathrm{kg}$ ) for 4 weeks. For details of procedures, see p. 459 . Values are means with their standard errors depicted by vertical bars. Mean values were significantly different from those of the controls: ${ }^{*} P<0.05$.

time-dependent manner: the effect started after 2 weeks, reaching the maximum inhibitory effect after 8 weeks of treatment (Fig. 2).

Blood cell counts and coagulation tests. Treatments with 4CA did not modify blood cell counts, $\mathrm{Hb}$ concentration, haematocrit value, mean platelet volume, platelet count, prothrombin time or activated partial thromboplastin time (data not shown).

Inhibition of thromboxane $B_{2}$ production. $\mathrm{TXB}_{2}$ release was measured in both dose-response and time-course experiments. In rabbits treated with 4CA $(5$ or $500 \mathrm{mg} / \mathrm{kg}$ for 4 weeks), $\mathrm{TXB}_{2}$ release, measured in PRP after AA-induced aggregation, was significantly reduced and the differences between the two doses were not statistically significant (Fig. 3(A))

In rabbits treated with $4 \mathrm{CA}(5 \mathrm{mg} / \mathrm{kg}) \mathrm{TXB}_{2}$ release during ADP-induced aggregation was significantly reduced after 2 weeks of treatment (Fig. 3(B)).

Ferric reducing ability of plasma assay. The administration of $4 \mathrm{CA}(5 \mathrm{mg} / \mathrm{kg})$ significantly increased the plasma antioxidant activity from 160 (SE 15) $\mu \mathrm{mol} / \mathrm{l}$ at time 0 to $310(\mathrm{SE} 30) \mu \mathrm{mol} / 1$ after 1 week $(P<0 \cdot 05)$ and to 380 (SE 50) $\mu \mathrm{mol} / \mathrm{l}$ after 3 weeks of feeding $(P<0 \cdot 05)$.

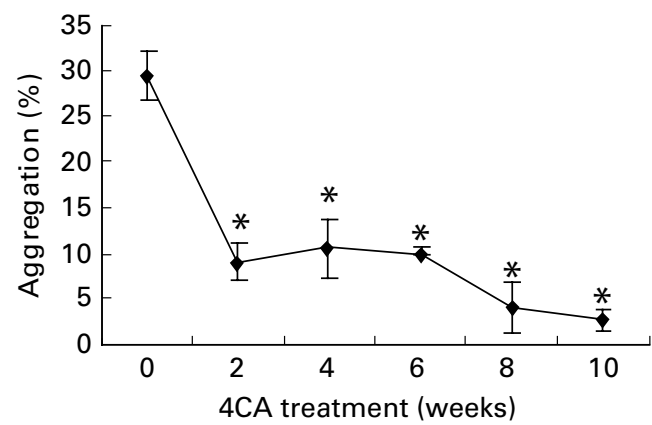

Fig. 2. Inhibition of platelet aggregation in blood samples from rabbits fed a standard diet enriched with $5 \mathrm{mg} / \mathrm{kg} p$-coumaric acid (4CA). For details of procedures, see p. 459. Values are means with their standard errors depicted by vertical bars. Mean values were significantly different from those at time $0:{ }^{*} P<0.05$. 

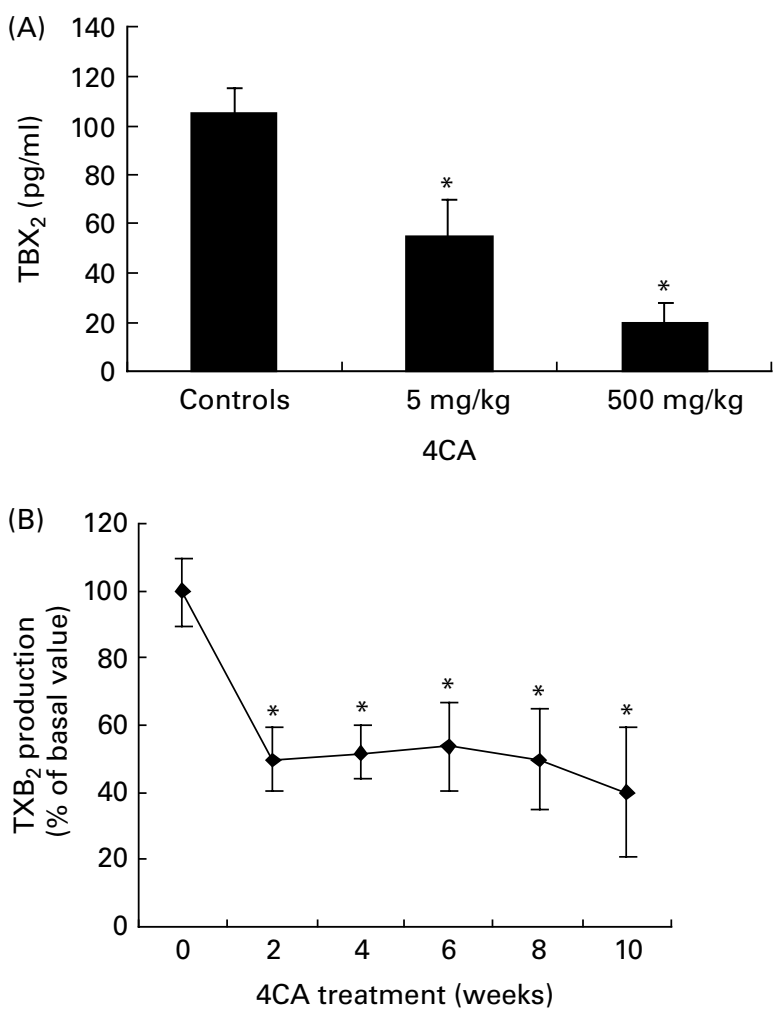

Fig. 3. $A$, Thromboxane $B_{2}$ (TXB2) production after arachidonic acid-induced platelet aggregation in blood samples from rabbits fed $p$-coumaric acid (4CA; 5 or $500 \mathrm{mg} / \mathrm{kg}$ ) for 4 weeks. B, TXB 2 production after ADP-induced aggregation in blood samples from rabbits treated with $4 C A(5 \mathrm{mg} / \mathrm{kg})$. For details of procedures, see p. 459. Values are means with their standard errors depicted by vertical bars. Mean values were significantly different from those of the controls $(\mathrm{A})$ or at time $0(\mathrm{~B}):{ }^{*} P<0.05$.

In vitro studies in human blood

Inhibitory effects of $4 C A$ on platelet function. All volunteers had normal platelet function and the vehicle alone $(2 \% 1 \mathrm{M}-$ $\mathrm{NaOH}$ ) had no effect on platelet aggregation. At the doses of $500 \mu \mathrm{M}$ and $1 \mathrm{mM}, 4 \mathrm{CA}$ significantly reduced ADP-induced platelet aggregation (35.6 (SE 2.35) \% and 55.18 (SE 4.01) \% of the basal level, respectively, $P<0.05$ ), while at lower concentrations $(10$ and $100 \mu \mathrm{M})$ it did not induce a significant effect (data not shown).

Platelet function measured as PFA-100 ${ }^{\mathrm{TM}}$ closure times. All volunteers had normal values and the vehicle alone $(2 \%$ $1 \mathrm{M}-\mathrm{NaOH}$ ) had no effect on closure time. Blood samples incubated for $60 \mathrm{~min}$ with $500 \mu \mathrm{M}-4 \mathrm{CA}$ showed a prolonged closure time. When incubated with $1 \mathrm{mM}-4 \mathrm{CA}$ the difference was statistically significant, using cartridges containing both collagen-epinephrine and collagen-ADP membranes (Table 1).

Inhibition of thromboxane $B_{2}$ production. At the doses of $500 \mu \mathrm{M}$ and $1 \mathrm{mM}, 4 \mathrm{CA}$ was able to reduce $\mathrm{TXB}_{2}$ release after ADP-induced platelet aggregation in PRP from healthy volunteers, with an $\mathrm{IC}_{50}$ of $371 \mu \mathrm{M}$.

Inhibition of prostaglandin $E_{2}$ production. Incubation of blood samples from healthy donors with lipopolysaccharide, in the presence of aspirin to block COX-1 activity, resulted
Table 1. Effect of blood incubation with different $p$-coumaric acid (4CA) doses on platelet function $\dagger$

(Mean values with their standard errors)

\begin{tabular}{|c|c|c|c|c|}
\hline & \multicolumn{2}{|c|}{$\begin{array}{l}\text { Collagen-epineph- } \\
\text { rine closure time (s) }\end{array}$} & \multicolumn{2}{|c|}{$\begin{array}{l}\text { Collagen-ADP } \\
\text { closure time (s) }\end{array}$} \\
\hline & Mean & SE & Mean & SE \\
\hline Control & $127 \cdot 3$ & $6 \cdot 8$ & $96 \cdot 2$ & 5.4 \\
\hline $500 \mu \mathrm{M}-4 \mathrm{CA}$ & 178.9 & 29.5 & $166 \cdot 0$ & 32.5 \\
\hline $1 \mathrm{mM}-4 \mathrm{CA}$ & $216 \cdot 7$ & $31.4^{\star}$ & 178.4 & $31.0^{*}$ \\
\hline
\end{tabular}

Mean values were significantly different from those of the control group: ${ }^{*} P<0.05$. †For details of procedures, see p. 459.

in marked induction of $\mathrm{PGE}_{2}$ formation. The vehicle alone $(2 \% 1 \mathrm{M}-\mathrm{NaOH})$ had no effect on $\mathrm{PGE}_{2}$ production, whereas 4CA reduced lipopolysaccharide-induced $\mathrm{PGE}_{2}$ generation with an $\mathrm{IC}_{50}$ of $126 \mu \mathrm{M}$.

\section{Discussion}

Platelets play a pivotal role in health and disease, given their central involvement in haemostasis and thrombosis. Treatment with drugs that specifically inhibit platelet function has proven to be beneficial in the prevention of thrombosis.

The relationship between a diet high in vegetable products and a decreased risk of thrombosis is well established, although the explanation for this is far from clear (Liu \& Willett, 2002). A number of studies have focused on the effects of dietary component, such as flavonoids on platelet function. Quercetin $(40-100 \mu \mathrm{M})$ and catechin $(100-420 \mu \mathrm{M})$ inhibit platelet aggregation in vitro, inhibiting the release of platelet hydrogen peroxide elicited by collagen, with almost complete suppression when used in combination (Pignatelli et al. 2000).

Resveratrol is another wine compound with several healthpromoting properties; the most widely accepted mechanism of resveratrol-mediated cardioprotection is its ability to inhibit platelet aggregation. At the concentration of $3.56 \mathrm{mg} / 1$, it lowers platelet aggregation by $50 \%$ in healthy volunteers (Bertelli et al. 1995). Moreover, resveratrol and quercetin inhibited thrombin-induced ADP and ATP secretion from platelets in a concentration-dependent manner (Kaneider et al. 2004).

In the present study we analysed the effect of another wine component, 4CA, which is also widely distributed in fruits, vegetables, cereals, tea and wine, mostly as conjugates. It is present as a free acid (about $22 \mathrm{mg} / \mathrm{l}$ ) and as $p$-coumaroyltartaric acid (about $139 \mathrm{mg} / \mathrm{l}$ ) in red wine (Ghiselli et al. 1998). Other abundant sources of 4CA are apples and berries $(69-1700 \mathrm{mg} / \mathrm{kg})$ and maize bran $(2.9 \mathrm{~g} / \mathrm{kg})$ (Stich, 1991; Clifford, 2000; Zhao et al. 2005).

Administered in vivo, 4CA was able to reduce significantly platelet aggregation induced by AA and ADP after 2 weeks of treatment and at a dose comparable to the daily intake for cinnamates (Clifford, 2000). In addition, the $\mathrm{TXB}_{2}$ production measurements were well correlated with platelet aggregation in both experiments.

In vitro, 4CA inhibited platelet aggregation without effects on prothrombin time, activated partial thromboplastin time, $\mathrm{Hb}$ concentration, haematocrit value, mean platelet volume and platelet count. In PFA- $100^{\mathrm{TM}}$ analysis, which simulates 
the process of platelet adhesion and aggregation induced by vascular injury, we also observed a significant effect of 4CA at high concentrations, using ADP as well as epinephrine cartridges. In vivo and in vitro studies suggested that 4CA modulates platelet aggregation through both $\mathrm{COX}$-dependent and independent mechanisms.

There are many platelet pathways which could be influenced by 4CA: polyphenols may inhibit platelet aggregation because of their antioxidant activity (Salvemini \& Botting, 1993; Neiva et al. 1999). 4CA is a potent inhibitor of LDL oxidation in vitro (Satué-Gracia et al. 1999; Morton et al. 2000). Owen et al. (2000) reported the antioxidant activity of 4CA against reactive oxygen species produced by hypoxanthine/xanthine oxidase and Lodovici et al. (2001) described its ability to reduce oxidative DNA damage induced in vitro by iron and cumene hydroperoxide. The present results show that the administration of $4 \mathrm{CA} \quad(5 \mathrm{mg} / \mathrm{kg})$ significantly increases plasma antioxidant activity after 1 week of treatment and more markedly after 3 weeks, confirming our previous data on the antioxidant activity of this molecule in vivo, on rat colon mucosa (Guglielmi et al. 2003).

It has also been suggested that the effect of polyphenols on platelet aggregation is related to the inhibition of the COX pathway, reducing the formation of $\mathrm{TXB}_{2}$, a potent aggregating and vasoconstricting agent. The anti-inflammatory effects of 4CA are controversial since it has anti-inflammatory activity if administered locally, but demonstrates no effects in vivo on carrageenan-induced paw edema when administered at $200 \mathrm{mg} / \mathrm{kg}$ per d, $1 \mathrm{~h}$ before carrageenan injection (Fernandez et al. 1998). Recently we demonstrated that an acute intestinal inflammation induced by dextran sulphate sodium can be inhibited by pretreatment with $4 \mathrm{CA}(50 \mathrm{mg} / \mathrm{kg})$ and that this effect was associated with the suppression of COX-2 expression and activity (Luceri et al. 2004). In the present study we demonstrate that the reduction of platelet aggregation induced by $4 \mathrm{CA}$ is correlated with decreased $\mathrm{TXB}_{2}$ production, associated with the inhibition of COX-1 and COX-2 activities.

In summary, 4CA, a dietary phenolic compound, acts as a potent systemic antioxidant and shows good antiaggregant properties at concentrations that can be obtained through regular consumption of vegetables, cereals, fruits or a moderate quantity of red wine. It has been estimated that the daily dietary intake for total cinnamates and hydroxybenzoic acid derivatives should be $1 \mathrm{~g} / \mathrm{d}$, corresponding to about $15 \mathrm{mg} / \mathrm{kg}$ per $\mathrm{d}$ in man (Clifford, 2000; Tomàs-Barberan \& Clifford, 2000).

Healthy subjects with no dietary restrictions had a relatively low concentration of 4CA in faecal water, ranging from 0.3 to $1.44 \mu \mathrm{M}$ (Jenner et al. 2005). However, in a recent paper by Garrait et al. (2006) the authors demonstrated that 4CA is absorbed by all the digestive tracts and, when orally administered, is mainly eliminated in the urine. Konishi et al. (2003), studying 4CA intestinal absorption, demonstrated that $4 \mathrm{CA}$ is actively transported by the colonic monocarboxylate transporter in Caco-2 cells; after an oral dose of $16.4 \mathrm{mg} / \mathrm{kg}$, the serum $C_{\max }$ was $165.7 \mu \mathrm{M}$ and the area under the curve was almost $3 \mathrm{~mm}$ in rats (Konishi et al. 2004).

Free phenolic acids are well absorbed but in foods they are mainly in bound form, esterified to cell wall polymers. It has been reported that IR irradiation or fermentation can liberate covalently bound phenolic compounds with antioxidant activities and that the irradiation of sesame seeds significantly increases the amount of free 4CA (Lee et al. 2005); these data suggest that some industrial processes can enrich the amount of free 4CA in food.

In conclusion, the present data suggest that dietary intervention with foods rich in 4CA may be a possible strategy for primary prevention of vascular diseases. Further studies on patients at risk could help to determine the potential beneficial effects of 4CA as an antiplatelet and systemic antioxidant agent for prevention and treatment of thrombotic diseases.

\section{Acknowledgements}

This work was financially supported by the Ministero della Università e della Ricerca Scientifica e Tecnologica, by the University of Florence, Italy, by the EU program Polybind QLRT 1999-00505 and by the Network of Excellence in Nutrigenomics, NuGO. We thank Mary Forrest for revision of the manuscript.

\section{References}

Andriambeloson E, Kleschyov AL, Muller B, Beretz A, Stoclet JC \& Andriantsitohaina R (1997) Nitric oxide production and endothelium-dependent vasorelaxation induced by wine polyphenols in rat aorta. Br J Pharmacol 120, 1053-1058.

Aviram M, Dornfeld L, Kaplan M, et al. (2002) Pomegranate juice flavonoids inhibit low-density lipoprotein oxidation and cardiovascular diseases: studies in atherosclerotic mice and in humans. Drugs Exp Clin Res 28, 49-62.

Benzie IF \& Strain JJ (1996) The ferric reducing ability of plasma (FRAP) as a measure of 'antioxidant power': the FRAP assay. Anal Biochem 239, 70-76.

Bertelli AA, Giovannini L, Giannessi D, Migliori M, Bernini W, Fregoni M \& Bertelli A (1995) Antiplatelet activity of synthetic and natural resveratrol in red wine. Int $J$ Tissue React 17, 1-3.

Born GV (1962) Aggregation of blood platelets by adenosine diphosphate and its reversal. Nature 194, 927-929.

Clifford MN (2000) Chlorogenic acids and other cinnamates - nature, occurrence, dietary burden, absorption and metabolism. J Sci Food Agric 80, 1033-1043.

Cordova AC, Jackson LS, Berke-Schlessel DW \& Sumpio BE (2005) The cardiovascular protective effect of red wine. J Am Coll Surg 200, 428-439.

da Luz PL \& Coimbra SR (2004) Wine, alcohol and atherosclerosis: clinical evidences and mechanisms. Braz J Med Biol Res 37, $1275-1295$.

de Gaetano G \& Cerletti C (2001) European project. FAIR CT 97 3261 Project participants. Wine and cardiovascular disease. Nutr Metab Cardiovasc Dis 11, 47-50.

Dell'Agli M, Galli GV, Vrhovsek U, Mattivi F \& Bosisio E (2005) In vitro inhibition of human cGMP-specific phosphodiesterase-5 by polyphenols from red grapes. $J$ Agric Food Chem 53, 1960-1965.

Demrow HS, Slane PR \& Folts JD (1995) Administration of wine and grape juice inhibits in vivo platelet activity and thrombosis in stenosed canine coronary arteries. Circulation 91, 1182-1188.

Duffy SJ, Vita JA, Holbrook M, Swerdloff PL \& Keaney JF Jr (2001) Effect of acute and chronic tea consumption on platelet aggregation in patients with coronary artery disease. Arterioscler Thromb Vasc Biol 21, 1084-1089. 
Fernandez MA, Saenz MT \& Garcia MD (1998) Anti-inflammatory activity in rats and mice of phenolic acids isolated from Scrophularia frutescens. J Pharm Pharmacol 50, 1183-1186.

Freedman JE, Parker C 3rd, Li L, Perlman JA, Frei B, Ivanov V, Deak LR, Iafrati MD \& Folts JD (2001) Select flavonoids and whole juice from purple grapes inhibit platelet function and enhance nitric oxide release. Circulation 103, 2792-2798.

Frei B \& Higdon JV (2003) Antioxidant activity of tea polyphenols in vivo: evidence from animal studies. J Nutr 133, 3275S-3284S.

Garrait G, Jarrige JF, Blanquet S, Beyssac E, Cardot JM \& Alric M (2006) Gastrointestinal absorption and urinary excretion of transcinnamic and p-coumaric acids in rats. J Agric Food Chem 54, 2944-2950.

Ghiselli A, Nardini M, Baldi A \& Scaccini C (1998) Antioxidant activity of different phenolic fractions separated from an Italian red wine. J Agric Food Chem 46, 361-367.

Guglielmi F, Luceri C, Giovannelli L, Dolara P \& Lodovici M (2003) Effect of 4-coumaric and 3,4-dihydroxybenzoic acid on oxidative DNA damage in rat colonic mucosa. Br J Nutr 89, 581-587.

Hong J, Smith TJ, Ho CT, August DA \& Yang CS (2001) Effects of purified green and black tea polyphenols on cyclooxygenaseand lipoxygenase-dependent metabolism of arachidonic acid in human colon mucosa and colon tumor tissues. Biochem Pharmacol 62, 1175-1183.

Jenner AM, Rafter J \& Halliwell B (2005) Human fecal water content of phenolics: the extent of colonic exposure to aromatic compounds. Free Radic Biol Med 38, 763-772.

Kaneider NC, Mosheimer B, Reinisch N, Patsch JR \& Wiedermann CJ (2004) Inhibition of thrombin-induced signaling by resveratrol and quercetin: effects on adenosine nucleotide metabolism in endothelial cells and platelet-neutrophil interactions. Thromb Res 114, $185-194$.

Kikura M, Levy JH, Safon RA, Lee MK \& Szlam F (2004) The influence of red wine or white wine intake on platelet function and viscoelastic property of blood in volunteers. Platelets 15, 37-41.

Konishi Y, Hitomi Y \& Yoshioka E (2004) Intestinal absorption of p-coumaric and gallic acids in rats after oral administration. J Agric Food Chem 52, 2527-2532.

Konishi Y, Kobayashi S \& Shimizu M (2003) Transepithelial transport of p-coumaric acid and gallic acid in Caco-2 cell monolayers. Biosci Biotechnol Biochem 67, 2317-2324.

Lee SC, Jeong SM, Kim SY, Nam KC \& Ahn DU (2005) Effect of far-infrared irradiation on the antioxidant activity of defatted sesame meal extracts. J Agric Food Chem 9, 1495-1498.

Liu S \& Willett WC (2002) Dietary glycemic load and atherothrombotic risk. Curr Atheroscler Rep 4, 454-461.

Lodovici M, Guglielmi F, Meoni M \& Dolara P (2001) Effect of natural phenolic acids on DNA oxidation in vitro. Food Chem Toxicol 39, $1205-1210$.

Luceri C, Guglielmi F, Lodovici M, Giannini L, Messerini L \& Dolara P (2004) Plant phenolic 4-coumaric acid protects against intestinal inflammation in rats. Scand $J$ Gastroenterol 39, $1128-1133$.

Morton LW, Croft KD, Puddey IB \& Byrne L (2000) Phenolic acids protect low density lipoproteins from peroxynitrite-mediated modification in vitro. Redox Rep 5, 124-125.
Neiva TJ, Morais L, Polack M, Simoes CM \& D’Amico EA (1999) Effects of catechins on human blood platelet aggregation and lipid peroxidation. Phytother Res 13, 597-600.

Olas B, Wachowicz B, Saluk-Juszczak J \& Zielinski T (2002) Effect of resveratrol, a natural polyphenolic compound, on platelet activation induced by endotoxin or thrombin. Thromb Res 107, 141-145.

Owen RW, Mier W, Giacosa A, Hull WE, Spiegelhalder B \& Bartsch H (2000) Phenolic compounds and squalene in olive oils: the concentration and antioxidant potential of total phenols, simple phenols, secoiridoids, lignans and squalene. Food Chem Toxicol 38, 647-659.

Patrignani P, Panara MR, Greco A, Fusco O, Natoli C, Iacobelli S, Cipollone F, Ganci A, Creminon C \& Maclouf J (1994) Biochemical and pharmacological characterization of the cyclooxygenase activity of human blood prostaglandin endoperoxide synthases. J Pharmacol Exp Ther 271, 1705-1712.

Pignatelli P, Lenti L, Pulcinelli FM, Catasca R, Saccani G, Germano G, Marcoccia A, Silvestri MA, Ghiselli A \& Violi F (2002) Red and white wine differently affect collagen-induced platelet aggregation. Pathophysiol Haemost Thromb 32, 356-358.

Pignatelli P, Pulcinelli FM, Celestini A, Lenti L, Ghiselli A, Gazzaniga PP \& Violi F (2000) The flavonoids quercetin and catechin synergistically inhibit platelet function by antagonizing the intracellular production of hydrogen peroxide. Am J Clin Nutr 72, 1150-1155.

Rasmussen SE, Frederiksen H, Struntze Krogholm K \& Poulsen L (2005) Dietary proanthocyanidins: occurrence, dietary intake, bioavailability, and protection against cardiovascular disease. Mol Nutr Food Res 49, 159-174.

Ruf JC (2004) Alcohol, wine and platelet function. Biol Res 37, 209-215.

Salvemini D \& Botting R (1993) Modulation of platelet function by free radicals and free-radical scavengers. Trends Pharmacol Sci 14, $36-42$.

Satué-Gracia MT, Andres-Lacueva C, Lamuela-Raventos RM \& Frankel EN (1999) Spanish sparkling wines (Cavas) as inhibitors of in vitro human low-density lipoprotein oxidation. J Agric Food Chem 47, 2198-2202.

Schubert SY, Lansky EP \& Neeman I (1999) Antioxidant and eicosanoid enzyme inhibition properties of pomegranate seed oil and fermented juice flavonoids. J Ethnopharmacol 66, 11-17.

Shanmuganayagam D, Beahm MR, Osman HE, Krueger CG, Reed JD \& Folts JD (2002) Grape seed and grape skin extracts elicit a greater antiplatelet effect when used in combination than when used individually in dogs and humans. J Nutr 132, 3592-3598.

Stich HF (1991) The beneficial and hazardous effects of simple phenolic compounds. Mutat Res 259, 307-324.

Tomàs-Barberan FA \& Clifford MN (2000) Dietary hydroxybenzoic acid derivatives - nature, occurrence and dietary burden. $J \mathrm{Sci}$ Food Agric 80, 1024-1032.

Vita JA (2005) Polyphenols and cardiovascular disease: effects on endothelial and platelet function. Am J Clin Nutr 81, 292S-297S.

Youssef F, Gupta P, Mikhailidis DP \& Hamilton G (2005) Risk modification in patients with peripheral arterial disease: a retrospective survey. Angiology 56, 279-287.

Zhao Z, Egashira Y \& Sanada H (2005) Phenolic antioxidants richly contained in corn bran are slightly bioavailable in rats. $J$ Agric Food Chem 53, 5030-5035. 